In April 1984 the results of the final examination for the first batch of students were announced. Of 22 students admitted to the course, 21 took the examination having passed all previous exams at the first or subsequent attempt. Of these, 12 were successful and the remainder will repeat the examination later.

I was present as an observer at the clinical and oral examinations in medicine of some of the students. The standard of history taking, physical examination, and diagnosis was extremely high. $X$ ray examinations were interpreted well and there was no difficulty in describing the use of various implements. Questions were in English and the answers were generally accurate in content, though the use of the language was often clumsy.

External examiners, two from India and two from Canada, were impressed. One Indian asked to take some of the graduates back to his hospital in India and was politely but firmly refused. A Canadian said that the candidates compared favourably with their counterparts in his country.

As the successful 12 begin their internships, I and my colleagues at the hospital already think that they are better prepared for the work than graduates of Indian medical colleges who have completed their internship programmes. Needless to say, they should be much superior in rural and community work.
The future

If initial enthusiasm has, as I believe, overcome the extreme practical and logistic difficulties, the prospects are bright. It will be important to maintain the vision, to resist the pull to conform, to shun inappropriate technology, and to train new, young teachers into the programme. Facilities are improving, experience has been gained, and the "product," the first batch of graduates, exists as a creditable example.

The possibility of postgraduate studies has been discussed from the beginning. If the present standard is maintained or improved there is no reason why teaching centres abroad should not be persuaded to accept Nepalese graduates after a short period of reorientation.

Students often ask me, "Will we be as good as doctors in the West?" This takes me back to my original question: what is a doctor? Moreover, what is a good doctor? The graduate of a London teaching hospital is doubtless superior in ordering and analysing a wide range of tests, but how would he manage a rural hospital in Nepal? I have no hesitation in telling my students that, for Nepal, they will become not only as good as Western doctors, but immensely better.

\title{
Falls from trees and tree associated injuries in rural Melanesians
}

\author{
PETER BARSS， PAISON DAKULALA， MICHAEL DOOLAN
}

\begin{abstract}
Falls from trees and other tree related injuries are the most common cause of trauma in some parts of rural Melanesia. A four year review of all admissions for trauma to the Provincial Hospital at Alotau, Milne Bay Province, Papua New Guinea, showed that $27 \%$ were due to falls from trees, and a further $10 \%$ were due to related injuries, such as being struck by a falling branch or a coconut. A questionnaire distributed to rural health centres showed that during the study period at least 28 villagers died from falls from trees before reaching hospital. Head and chest trauma were common causes of death. Many injured patients were boys. Forearm fractures were the most common injuries, but more serious injuries were also frequently encountered. Trees responsible for most deaths and injuries included the coconut palm, betel palm, mango, and breadfruit.

There are many strategies for preventing such injuries; perhaps the most important is to stop small boys climbing tall trees. Such falls are a serious occupational hazard for many subsistence farmers.
\end{abstract}

Provincial Hospital, Alotau, Milne Bay Province, Papua New Guinea PETER BARSS, MD, DTM\&H, medical superintendent

University of Papua New Guinea

PAISON DAKULALA, medical student

University of Sydney, Australia

MICHAEL DOOLAN, medical student

Correspondence to: Dr Peter Barss.

\section{Introduction}

Climbing trees is an important part of rural life in many tropical countries. Children often climb while playing. Adults and children commonly climb to collect the harvest from various trees, and people occasionally climb trees in pursuit of animals, such as the cus-cus or fruit bat. Some trees are very high, and falls can result in severe injury. Falling coconuts, falling branches, and poorly felled trees are also hazards. We noted that many of our admissions for trauma in Milne Bay Province, Papua New Guinea, were due to falls from trees and other tree associated injuries. We report here a four year review of patients with such injuries. This review includes all patients who survived to reach hospital. To determine roughly how many other villagers died before reaching hospital, we circulated a questionnaire to the 30 rural health centres who refer patients to us. The findings reported here may dispel some misconceptions about an easy idyllic rural life in the Pacific Islands.

\section{Patients and methods}

The provincial hospital, Alotau, is a 100 bed hospital with three doctors and is the only hospital for 130000 Melanesians living mainly in scattered hamlets on tropical islands. Most seriously injured patients, including those with displaced fractures, are referred from the 30 rural health centres in the province. Numerous minor fractures are dealt with at rural health centres and are not included in our statistics.

All admissions for trauma, excluding lacerations, from October 1978 to 30 September 1982 were reviewed by studying hospital admission and discharge books and operating theatre records. Patient charts were then checked for details. Patients with uncomplicated soft tissue injuries and minor head injuries who were conscious on arrival were excluded from the study. About $5 \%$ of patients' charts could not be found; if insufficient detail was 
available these patients were also excluded. A questionnaire was sent to each of the 30 provincial rural health centres. This asked how many patients had died from a tree fall either in the village or at the health centre before reaching hospital, how they had died, and what sort of tree had been involved.

\section{Results}

Falls from trees and other tree associated injuries were responsible for $41 \%$ of admissions for trauma. Between 1978 and 1982, 355 patients were admitted to Alotau Hospital with trauma. Of these, $97(27 \%)$ had injuries caused by falling from trees and 35 $(10 \%)$ had other tree associated injuries ( 21 were struck by a falling tree or branch; nine were struck by a falling coconut; two tripped and fell off a log; and four had other injuries). Inexperienced or older axemen occasionally managed to fell trees on themselves. Falling trees in the tropics often pull down branches from other trees because of numerous attached vines. Limbs of large rain forest trees killed by slashing and burning when traditional gardens are being prepared may also fall on people. Huge rain forest trees are sometimes blown over in cyclones and often block bush trails. People are occasionally injured climbing over such trees or crossing log bridges.

The youngest patient injured by falling from a tree was 3 and the oldest over 60 . Forty three per cent of those who fell from trees were aged $3-9$ and $31 \%$ aged $10-16 ; 25 \%$ were adult. Eighty four per cent were male. Patients injured in tree falls spent longer in hospital (40 days on average) than patients suffering other injuries (27 days). This represents a considerable financial burden for the health service. Inpatient stays are longer than in other hospitals because of the difficulty of repatriating patients to remote islands.

Many of our patients were unable to specify the type of tree from which a fall had occurred. These were usually bush trees. The trees specified were coconut (18 cases), mango (14), and betel nut (10).

The types of injuries seen with tree falls were numerous. Of fractures of the arm, 40 were of the radius and ulna, 13 of the elbow, six of the humerus, and two of the clavicle. Of fractures of the leg, nine were of the tibia and 10 of the femur. Thirteen of the fractures were open, including five of the radius and ulna, one of the humerus, three of the femur, two of the tibia, and two of the skull. Three patients fractured both forearms. One supracondylar fracture required repair of a torn brachial artery. One patient suffered an epidural haematoma and recovered. Two patients had large depressed skull fractures: one was complicated by hemiparesis and epidural clots, and the other was compound with a small amount of pulped brain. The three other head injuries were unspecified, and all the patients died. Three patients had rib fractures. Five patients became paraplegic owing to spinal injuries

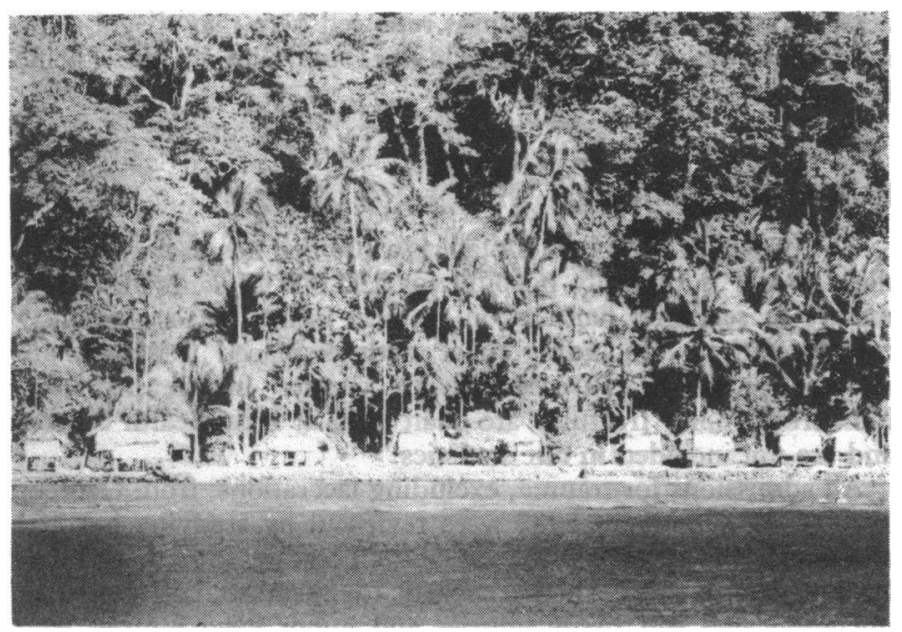

FIG 1-Milne Bay coastal hamlet with coconut palms and smaller betel palms in the foreground and bush trees in the background. and only one recovered the use of his legs. Of the patients with abdominal injuries, three suffered a ruptured spleen, three a penetrating wound of the rectum with peritonitis, and one acute gastric dilatation.

Rural survey of deaths due to falls from trees-Thirty questionnaires were sent to our rural health centres to determine how many village people had died in the surrounding area after falling from trees without reaching hospital. Twenty four were returned, and we learnt that at least 28 villagers had died in such circumstances from 1978 to 1982 . Many had died instantly in the village from head or chest injuries. A few had survived long enough to reach the

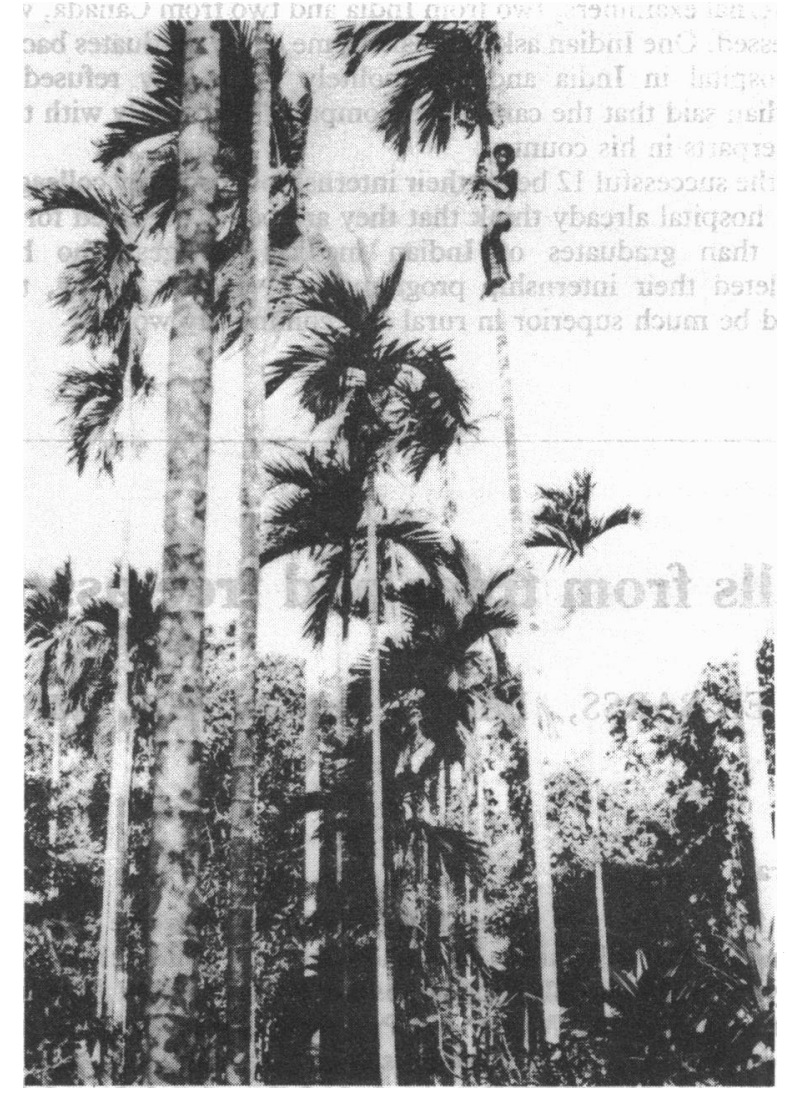

FIG 2-Betel palm climber with loop of bush twine between his feet.

nearest health centre. The deaths were due to falls from coconut trees (five cases), betel nut trees (four), breadfruit trees (five), bush trees (four), and unspecified trees (10).

\section{Clinical management of fractures}

Many of our patients with fractures arrive late from remote centres, up to two weeks or more after the injury. Displaced fractures of the distal radial metaphysis or type two epiphyseal injuries of the distal radius were the most common injuries. They were reduced by closed manipulation with a single injection of 2 $\mathrm{mg}$ intravenous ketamine/ $\mathrm{kg}$ as an anaesthetic. This worked well provided that the person doing the reduction had reasonable skill. Delayed treatment of such fractures is usually surprisingly successful, because oedema has often decreased by the time of arrival. This facilitates palpation of the fracture line. Reduced fractures are held in a "sugar tong" plaster slab. This is carefully moulded and secured with an elastic bandage and seldom needs changing. It has not resulted in ischaemic problems despite minimal ward supervision. Other types of fractures of the radius and ulna were managed according to general orthopaedic principles, with a few adults requiring open reduction and plating. Such operations were usually done under axillary block anaesthesia.

Many of the elbow injuries were supracondylar fractures. They

क

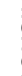

के

(a)

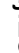

,

,

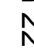

,

. 


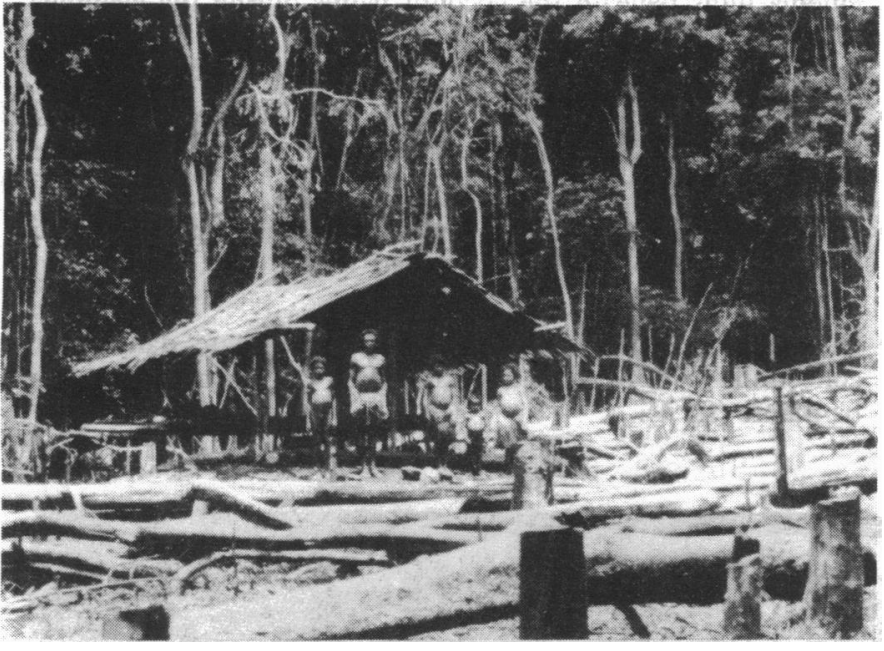

FIG 3-New rain forest garden being prepared by cultivators.

were managed by closed reduction with good results in all cases, even though some presented rather late. There were a few cases of trapped medial epicondyle or displaced lateral condyle that required open reduction and pinning. Ketamine anaesthesia was used. A patient with a fractured shaft of the humerus was managed with a collar and cuff and sugar tong splint. Patients with fractured clavicles were treated with a triangular bandage sling tied tight enough to support the elbow. Figure of eight bandages are impractical in the tropics. Fractured tibias were handled by closed reduction and casting, again under ketamine anaesthesia. Fractured femurs were managed by skin traction alone; this resulted in shortening in some cases but was the simplest treatment given our limited staff and facilities.

All patients with compound fractures were taken immediately to theatre, where the wound was cleaned, debrided, and reduced under full sterile conditions. Delayed closure was practised for most wounds. Early arrivals did well. Late arrivals, who usually already had bad infections on admission, often had a prolonged hospital stay until their osteomyelitis had been eradicated.

Head injuries were managed with a hand brace, perforator, burrs, plus a few other instruments such as bone rongeurs. Ketamine anaesthesia was used, together with diazepam, atropine, and endotracheal intubation.

Management of such injuries in a rural hospital may give satisfying results. Only open fractures, head injuries, and abdominal trauma are handled at night. Most fractures are reduced in theatre during the daytime with adequate staff present and the patient's stomach empty. Patients are almost always kept in at least overnight for observation after reduction. We work without anaesthetists but with good theatre staff. Ketamine is a useful and safe anaesthetic and has never given any serious complications in several years of use. It is so quick and safe that we use it almost exclusively for simple closed reductions, and also for open reductions in children. In longer procedures diazepam is used together with ketamine. In procedures such as bone plating in adults, axillary block has been the best anaesthetic for our purposes. Intravenous regional blocks have been useful for the management of forearm fractures in some adults and teenagers.

\section{Discussion}

Injuries associated with trees, particularly falls from trees, are common in the hamlets of the tropical islands and mountains of Milne Bay Province, Papua New Guinea. There are no cities in the province, and most patients come from rural villages, which are surrounded by tall trees of several types (fig 1). Roads are few, and most travel is by canoes, boats, or air. Tree associated injuries constituted a major proportion $(41 \%)$ of the trauma seen in this hospital. Ebong, writing from Ibadan, Nigeria, stated that falling from trees is a rare cause of injury in the tropics, although it was the most common cause of paraplegia and quadriplegia at Ibadan. ${ }^{1}$ Our experience may differ because we are serving a predominantly rural people, most of whom have no access to roads or motor vehicles. It would seem that for people such as these, particularly those who cultivate coconut palm, the betel palm, breadfruit, and mango trees, falling from these high trees or being struck by falling coconuts is one of the main sources of serious traumatic injuries. As people move to towns motor vehicle accidents, fights, and other causes of trauma seem to take the place of tree injuries.

The most common injuries were forearm fractures, but other fractures of arms and legs were frequent. Compound fractures were relatively common and often infected with osteomyelitis by the time that the patient reached hospital. Infected fractures accounted for some of the longest hospital stays. Head and spinal injuries were less common but serious when they occurred, accounting for at least five deaths. A few patients became paraplegic, and most of these are presumed to have died at home after discharge.

Our health centre survey showed that at least another 28 patients died after falling from trees without reaching hospital. All died from head injuries, and a few also had thoracic, abdominal, or spinal injuries. Most of these deaths resulted from falls from coconut, betel nut, or breadfruit trees.

Most village tree climbers do not use any safety equipment. A few use a small loop of rope or bush twine that extends from one foot to the other and serves to hold their feet close together as they work their way up the tree using the soles of their feet and their hands (fig 2). Climbers may reach great heights. Coconuts hang from the top of a tall, slender unbranched trunk that sways to and fro in the wind. It is not uncommon for trees to attain a height of 24 to 30 metres $^{2}$; one palm 35 metres tall has been recorded. ${ }^{3}$ Coconut palms increase in height fairly rapidly until fruit bearing begins, which occurs sometimes at less than six metres, and then grow steadily until senility at 80 to 100 years (J Woodroofe, personal communication). Thus a fall from a mature coconut palm could be equivalent to a fall from a 10 storey building. In a fall from a tree 25 metres high the victim will acquire a velocity of 80 kilometres/hour by the time that he strikes the ground. This is comparable to velocities encountered in motor vehicle crashes. A serious injury is almost certain to occur. The tall palm Cocos nucifera, variety typica, is much more common in Milne Bay than the dwarf palm, variety nana (J Woodroofe, personal communication). The betel palm, Areca catechu, whose seed is used widely here as a mildly addictive masticatory, also has a long, smooth, slender, generally unbranched stem up to 30 metres tall and grows continuously until senesence. ${ }^{4}$ When a climber falls from a coconut or betel palm there is nothing to grasp on the way down. Mangifera indica, the most common mango species here, reaches heights of up to 40 metres. The breadfruit tree, Artocarpus altilis, is up to 20 metres high. ${ }^{5}$ Falls from mango trees may occur when branches break off as the climber works his way out towards the fruit.

A large proportion of the injured climbers were children. Some injuries occurred at play; however, children are often sent up the tall slender betel palm because of their light weight. One young boy sustained three fractures in one arm, two of them compound, when he fell from a betel palm. At least one spinal injury occurred in a boy from a boarding school who climbed a tree while home in his village on holiday. He was not in shape for climbing. Old people are also more prone to falls: an old man was found dead at the foot of a tree with a fractured cervical spine and head injury after climbing for mustard leaf to use with his betel nut.

Tree associated injuries were most commonly due to being struck by a falling tree or branch. Preparation of a new garden from tropical rain forest by shifting cultivators needs extensive tree felling (fig 3). Injuries may occur at the time of felling or later, as large trees are sometimes ring barked or burnt and left standing. Branches may later drop unexpectedly into the garden. Dead trees or branches found along bush trails may also drop or blow over suddenly. Many of the victims struck by trees were old men who 
were felling; perhaps they did not move quickly enough when the tree started to fall. An unhusked dry coconut may weigh between one and four kilograms. A two kilogram coconut that falls from a 25 metre tree may reach a velocity of 80 kilometres/hour at ground level, and may strike with a force of 1000 kilograms or more. The only serious injuries caused by falling coconuts occurred in small children; one child suffered a depressed skull fracture with hemiplegia and coma, and another a large epidural haematoma. Both recovered after surgical treatment.

\section{STRATEGIES FOR DECREASING FALLS FROM TREES AND TREE ASSOCIATED INJURIES}

- Only fit, young adults, experienced as climbers, should go up the taller varieties of trees. Children, especially those under 10, should be discouraged from climbing trees, particularly the taller types. Old people should also be discouraged from climbing trees. People should not use small children for harvesting fruit and seeds from tall trees. Monkeys have been trained to harvest coconuts in some countries, but there are no monkeys in Papua New Guinea.

- Small children often try to go up and down betel trees quickly, sliding fast on the way down. A climber should rest before starting down with his harvest.

- Time of day and weather may affect falls. Climbing after rain may be dangerous. When the sun is hot the tree is also said to be slippery.

- A safety belt, such as is used by telephone linesmen, might be helpful when climbing coconut and betel palms. Village people, however, might not wish or be able to purchase such an item. Climbing mango trees is avoided by some people by using a bamboo pole with a small net. Some people throw stones to dislodge the ripe fruit.

- Small children should be discouraged from playing near coconut palms to avoid injuries caused by falling coconuts. Locating dwellings away from coconut palms may also help. Dry coconuts sometimes fall and strike people climbing the trunk of the tree. When climbing coconut trees, you must be careful not to grasp a bunch of coconuts as a support; one man fractured his cervical spine when a bunch he was holding on to pulled loose.

- Old men should be careful when felling trees. Axemen must be wary of branches and other trees pulled down by vines as a tree falls.

- Epileptics should not climb tall trees; one epileptic fell from a mango tree during a fit and died; an epileptic child fractured a femur after a fall during a fit.

- People with malaria and other illnesses should not climb.

- Climbers must be careful using bush knives in trees. One man cut his arm badly, fell, and died.

- It is wise to check for snakes in the tree before climbing. People have reached up to pull themselves to the top of the tree and then fallen when they were startled by a snake peering at them.

- It is unwise to consume palm wine at the top of a coconut tree. This has resulted in falls in other provinces where palms are tapped for this purpose.

- Safety helmets can be used by workers on coconut plantations. One missionary here had been wearing a safety helmet for years during his work on a coconut plantation. He was one day hit by a coconut, which burst open as it struck the helmet; he sustained a fit of hysterical laughter, thought to be due to a mild head injury. A man stationed with the army on a plantation here during the second world war told us that the troops used to view cinema films beneath the coconut palms during the evenings. After one man was injured by a falling coconut the troops began wearing their military helmets during the screenings.

- Improved maintenance of rain forest trails would decrease injuries sustained climbing over fallen trees or crossing inadequate or rotten tree bridges.

- In Sabah, Malaysia, it is said that bamboo poles up to 21 metres long with a hooked knife attached to the end are used for harvesting coconuts.

- In Burma special ladders are used to facilitate daily toddy collections from palms, as portrayed on the Burmese five kyat banknote (fig 4).

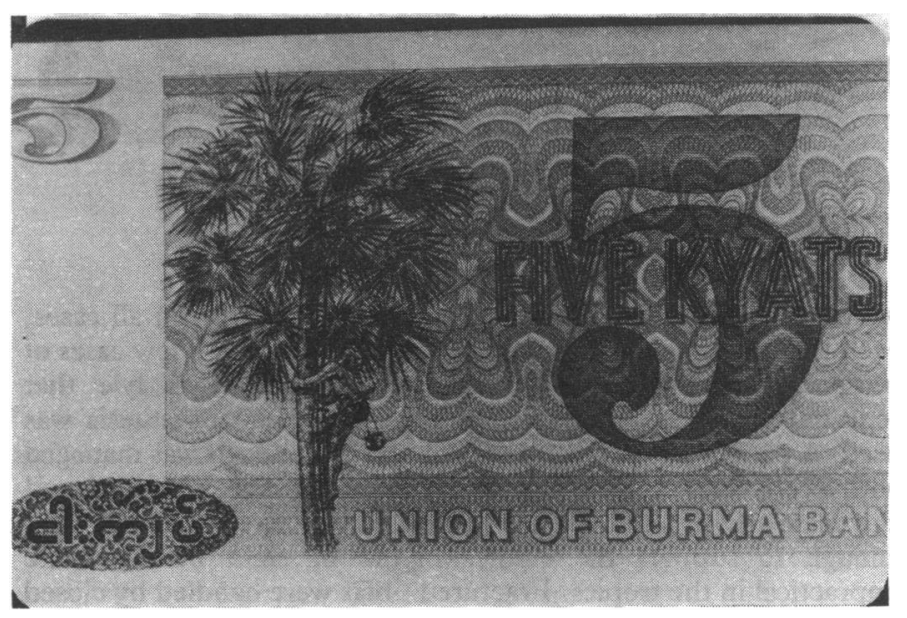

FIG 4-Burmese banknote showing special ladder for collecting toddy wine.

\section{Conclusion}

It seems that tropical village life has its own varieties of occupational traumatic hazards. Urban man in the Pacific has exchanged the hazards of falling from tall tropical trees for other types of trauma. Falls from trees usually affect only one person, motor vehicle accidents often many. Rousseau expressed the view that many of the serious disasters befalling man are due to the fact that he chooses to live in towns rather than in a more natural rural condition. ${ }^{6}$ There may be some truth in this simple notion; however, the idea that a return to an isolated village existence would eliminate most traumatic deaths is probably fallacious, at least for the tropics. A tropical islander is imagined as reclining beneath his trees, languidly plucking the ever present harvest. The truth is that most villagers work hard planting their gardens and often risk their lives climbing high to reap the produce of their tallest trees. One village man expressed his view of the problem of falls from trees as follows: "If a man falls from a tall coconut tree it's unnecessary to go along to check his condition because surely he will be dead. If he has fallen from a short coconut we will go to see if he can be helped."

We thank our rural health staff for providing some of the information; Mary Isikel Phillips for retyping the many drafts of this paper; J Woodroofe for information about tropical trees; and Professor A Whitford, emeritus professor of astronomy at the University of California, Santa Cruz, for help with the physics of falling climbers and coconuts.

\section{References}

1 Ebong WW. Falls from trees. Tropical and Geographical Medicine 1978;30:63-7 2 Smith HH, Pope FAG. Coconuts, the consols of the East. London: Tropical Life Publishing

3 Child R. Coconuts. London: Longman, Tropical Agricultural Series, 1964:32.

4 Purseglove JW. Tropical crops-monocotyledons. London: Longman, English Language Book Society, 1975:436.

5 Purseglove JW. Tropical crops-dicotyledons. London: Longman, English Language Book

6 Durant $W$. The story of philosophy. New York: Simon and Schuster, 1953:173. 